\title{
UPPER LIMITS TO THE FLUX OF HIGH ENERGY $\gamma$-RAYS FROM SELECTED QUASI-STELLAR AND OTHER SOURCES, USING THE CERENKOV TECHNIQUE (*)
}

\author{
By C. D. Long, N. A. Porter and T. C. Weekes \\ (University College Dublin, Eire.) \\ By J. F. Fruin and J. V. Jelley \\ (Atomic Energy Research Establishment, Harwell, United Kingdom.)
}

Résumt. - On a calculé une limite supérieure du flux de rayons $\gamma$ d'énergie supérieure à $510^{12} \mathrm{eV}$ reçu sur la Terre et provenant des sources quasi-stellaires $3 C$ 147, $3 C$ 196, $3 C$ 273, de la Nébuleuse du Crabe et de la variable magnétique $53 \mathrm{Cam}$. On trouve dans tous les cas un flux de l'ordre de $10^{-10}$ photons $\mathrm{cm}^{-2} \mathrm{~s}^{-1}$. Les limites supérieures de l'énergie émise par la source sont de $5 \times 10^{47}$ ergs $s^{-1}$ pour les sources quasi-stellaires, et $5 \times 10^{35}$ ergs $5^{-1}$ pour la Nébuleuse du Crabe, si l'on suppose l'absorption négligeable. On discute certains mécanismes d'absorption.

ABSTRAOT. - Upper flux limits at the earth for $\gamma$ rays of energy greater than about $5 \times 10^{12} \mathrm{eV}$, have been established for the quasi-stellar sources $3 C$ 147, $3 C$ 196, 3C 273, the Crab Nebula, and the magnetic variable 53 Cam. They are all of the order $10^{-10}$ photons $\mathrm{cm}^{-2} \cdot \mathrm{s}^{-1}$. Corresponding upper energy limits at emission are of the order $5 \times 10^{47}$ ergs s $^{-1}$ for the quasi-stellar sources, and $5 \times 10^{35}$ ergs $s^{-1}$ for the Crab Nebula, if $\gamma$-ray absorption is assumed negligible. Possible absorption mechanisms are discussed.

Резюме. - Вычислен верхний предел потока лучей $\gamma$ с энергией превыпающей $5.10^{12} 9 \mathrm{~B}$, полученный на Земле и происходящий из квази-звездных источников 3с 147, 3с 196, 3с 273, из туманности Краба и из магнитной переменной 53 Сам. Во всех случаях найден поток порядка 1011 форотовов/ $\mathrm{cм}^{2}$ сек. Верхние пределы излученвой источником энергии - $5 \times 10^{47}$ эрг/сек для источннков квазиэвездных, и $5 \times 10^{35}$ эрг/сек для Краба, если предположить поглощение пренебрежимым. Обсуждены некоторые механизмы поглощения.

While not strictly within the confines of the title of this symposium, since the observations were carried out below the atmosphere, a report is presented on the search for $\gamma$-rays in the energy region $\geqslant 5.10^{12} \mathrm{eV}$, from five selected objects. Details of the technique will not be presented, since these have already been discussed elsewhere [1]. The essential features are however summarised as follows: - High energy $\gamma$-rays in the primary cosmic-radiation produce extensive cosmic-ray air showers in the atmosphere, which showers differ in but a few respects from those produced by the much more abundant charged particle component of the primary radiation. Associated with the charged secondary particles, there exist short flashes of Čerenkov light (of duration $\sim 18^{-8} \mathrm{~s}$ ) which can readily be detected against the fluctuations of the background light of the night-sky.

$\left(^{*}\right)$ Work supported inpart by the European Office of Aerospace Rosearch, United States Air Force, under grant EOAR-63-80.
Since the pool of light from a single shower covers approximately $10^{5} \mathrm{~m}^{2}$ on the ground, and the direction of the primary particle or $\gamma$-quantum can be defined to approximately $2^{\circ}$, the Cerenkov technique provides a method for searching for possible point sources of $\gamma$-radiation from selected objects in the sky. The energy threshold of the existing equipment is $\sim 5.10^{12} \mathrm{eV}$ While it must be appreciated that the only discrimination we have against the high background of isotropic flux of charged particles is a directional one, we claim nevertheless that in the rather limited energy range, no other existing technique has comparable sensitivity.

The observations were carried out during January to April 1964 at a dark site at Glencullen in the Wicklow mountains, near Dublin, to which the installation was transferred from Harwell in 1963. For various technical and other reasons, the original method of drift scans was abandoned, in favour of sets of observations carried out alternately on and off the source. A summary of the 


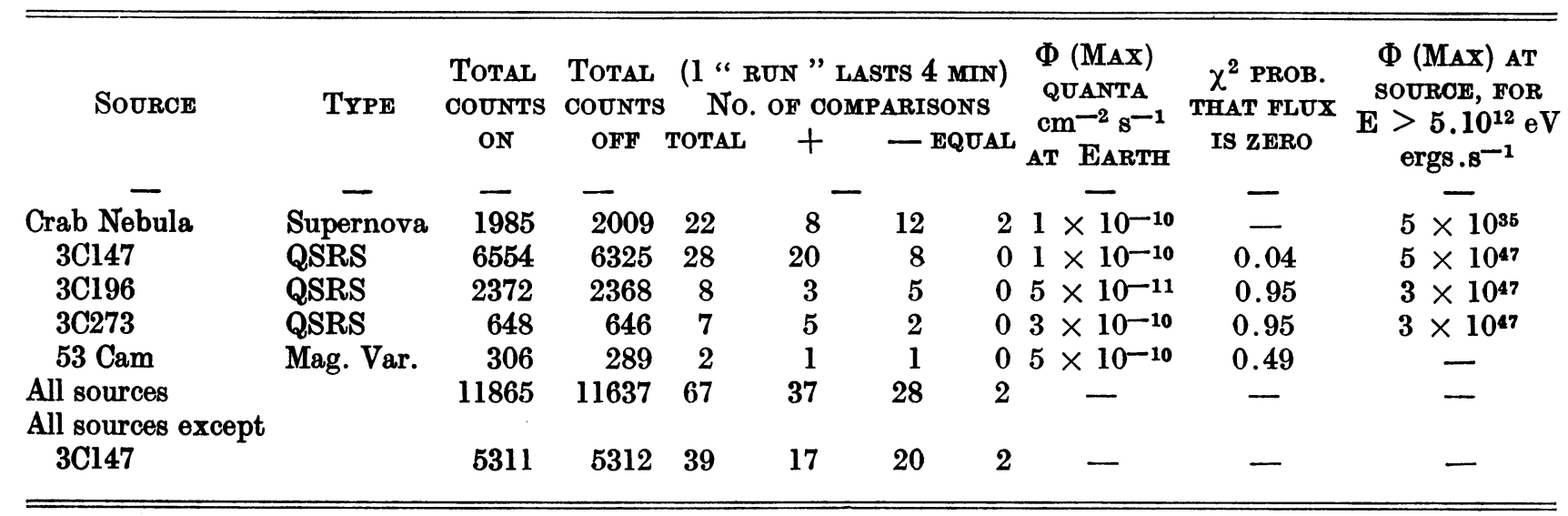

results, already published elsewhere [2] are shown in Table I. Columns 6 and 7 refer to the number of runs which gave a positive or negative effect on the sources respectively.

As will be seen, there is no positive evidence for $\gamma$-rays from any of the objects selected, at the flux limits deduced, except for the source $3 \mathrm{Cl47}$ for which the enhancement of counts on the source appears to be approaching statistical significance, both on total counts and on individual runs.

It should be pointed out, however, that in this one case there is a bright star, $\alpha$ Aurigae, 2.5 outside the limit of the geometrical field of view of the light receiver (half-angle of the acceptance cone also $2.5^{\circ}$ ), and modulation effects due to atmospheric scintillation cannot be ignored, in spite of a servo loop to maintain the average light intensity constant. These effects have also been discussed by CHODAKOv [3] whose group has for some years been developing this same technique for searching for $\gamma$-rays, from several radio sources other than the quasi-stellar objects. We are also concerned with possible effects due to the varying ambient magnetic field on the phototubes, during changes of orientation; preliminary indications are, however, that these are not significant. Both effects will receive further attention this coming winter.

NrkisHov [4] has suggested that photon-photon interactions between $\gamma$-rays emitted from remote objects, and optical photons in intergalactic space, may be a serious source of attenuation of these $\gamma$-rays over great distances. However, the " thermal" photon density assumed by Nikishov in

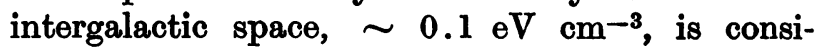
dered by G. R. BURBIDGE (private discussion) to be too high, probably by two orders of magnitude.

We would suggest tentatively that absorption of $\gamma$-rays by this process may still be important, not across intergalactic space, but within the $\gamma$-ray sources themselves, if such $\gamma$-rays originate close to the optical cores of the quasi-stellar objects which are believed to have absolute magnitudes of -26 to -25 (for $3 \mathrm{C} 273$ and $3 \mathrm{C} 48$ respectively, see Greenstein and Sohmidt [5]). In any event, a more thorough analysis of the possible role of this absorption process is indicated, as a possible explanation for the apparent absence of high-energy $\gamma$-rays, from what are believed to be the most powerful energy sources in the universe.

Manuscrit reçu le 17 septembre 1964.

\section{REFERENCES}

[1] J hLley J. V. and Porter N. A., 1963, Q. J. $R$. A. S., 4, 275.

[2] Fruin J. F., Jelley J. V., Long C. D., Porter N. A. and Wemzes T. C., 1964, Physics Letters, 10, No. 2, 176.

[3] Chudakov A. E., Dadykin V. L., Zatsepin V. I. and Nesterova N. M., 1964, Proc. Internat. Conf. Cosmic Radiation, Jaipur, India, 4, 199. [4] Nikishov A. I., 1962, J. E. T. P. (Soviet Physics), 14, No. 2, 393.

[5] Greenstein J. L. and Schmidt M., 1964, Astrophys. J., 140, No. 1, 1. 